\title{
Setting Reaction of Dental Resin-Modified Glass Ionomer Restoratives as a Function of Curing Depth and Postirradiation Time
}

\author{
Young Kyung Kim, ${ }^{1}$ Kyo-Han Kim, ${ }^{2}$ and Tae-Yub Kwon ${ }^{2}$ \\ ${ }^{1}$ Department of Conservative Dentistry, School of Dentistry, Kyungpook National University, Daegu 700-412, Republic of Korea \\ ${ }^{2}$ Department of Dental Biomaterials, School of Dentistry, Kyungpook National University, Daegu 700-412, Republic of Korea
}

Correspondence should be addressed to Tae-Yub Kwon; tykwon@knu.ac.kr

Received 20 August 2014; Accepted 1 October 2014

Academic Editor: Qingrui Zhang

Copyright (C) 2015 Young Kyung Kim et al. This is an open access article distributed under the Creative Commons Attribution License, which permits unrestricted use, distribution, and reproduction in any medium, provided the original work is properly cited.

\begin{abstract}
Specular reflectance Fourier transform infrared (SR-FTIR) spectroscopy was used to study the setting reaction of dental resinmodified glass ionomer (RMGI) restoratives as a function of curing depth and postirradiation time. Two light-cure and one tricure RMGI materials were selected and used according to the manufacturers' instructions. Samples were prepared by filling the mixed materials into custom-made molds and then light-irradiating using a dental curing light. The degree of conversion and the extent of acid-base reaction of the materials at different depths $(0,1,2$, and $4 \mathrm{~mm})$ and postirradiation times (10 min, 1 day, and 7 days) were determined using SR-FTIR spectroscopy in conjunction with the Kramers-Kronig (K-K) transformation. The setting reaction was also investigated using microhardness measurements. The results showed that the depth of cure increased over time by the continuous acid-base reaction rather than photopolymerization or chemical polymerization. Microhardness tests seemed less suitable for studying the setting reaction as a function of postirradiation time, probably due to softening from the humidity. Analysis using specular reflectance in conjunction with the K-K algorithm was an easy and effective method for monitoring the setting reaction of dental RMGI materials.
\end{abstract}

\section{Introduction}

Dental glass ionomers (GIs) are water-based materials that set by an acid-base reaction between a polyalkenoic acid and fluoroaluminosilicate glass $[1,2]$. Resin-modified glass ionomers (RMGIs) were developed to overcome the major drawback of conventional GIs, sensitivity to water during the initial setting, by incorporating resin monomers into an aqueous solution of polyacrylic acid [3]. The primary resin incorporated in RMGIs is a hydrophilic monomer such as 2hydroxyethyl methacrylate (HEMA) [4]; a small amount of dimethacrylate monomer may be additionally incorporated to form crosslinked poly-HEMA during polymerization [5]. The setting reaction of RMGIs includes radical polymerization (by either light-cure or self-cure) to form a polymer network along with a fundamental acid-base reaction to form a GI polysalt matrix $[6,7]$.
Light-cure RMGI restoratives may not adequately set when placed in bulk because of the reduced penetration of light into the deeper regions of the restoration, which may not be sufficient to initiate photopolymerization [8]. Tricure RMGI restoratives were developed in order to ensure that these deeper regions of the restoration are properly cured [7-9]. The manufacturers claim that these products undergo chemical polymerization in addition to an acid-base reaction and photopolymerization ("tricure"), which consequently increases the depth of cure [4].

One of the most common methods for evaluating the setting behavior of light-cure or tricure RMGI restoratives as a function of curing depth is measuring the hardness $[4,10]$. Although microhardness tests are convenient, they fail to differentiate the relative contribution between radical polymerization and acid-base reaction because the two types 
of reactions proceed simultaneously. A previous Fourier transform infrared (FTIR) spectroscopy study demonstrated that the visible light-curing process, for either light- or tricure RMGIs, greatly reduces the salt formation (acid-base reaction) rate during the early setting stages, which is likely due to rapid polymer network formation [7]. Another FTIR study showed that the acid-base reaction is greatly delayed in RMGIs compared to conventional GIs [11]. A differential scanning calorimetry (DSC) study showed that early lightactivation of RMGIs may limit the acid-base reaction and result in a varied material structure [12]. However, there is still limited experimental and clinical information available concerning the setting reaction of RMGI restorative materials as a function of curing depth and postirradiation time.

In this in vitro study, we investigated the monomerto-polymer conversion and the acid-base reaction of three commercial RMGI restoratives at different depths and postirradiation times using an optical microscope connected to an FTIR spectrophotometer. We also compared the FTIR analysis results with the measured microhardness of the materials. It was assumed that each measured microhardness value reflects the surface hardening by the contribution of both the polymerization reaction and acid-base reaction at a specified depth and postirradiation time.

\section{Materials and Methods}

2.1. Sample Preparation. Two light-cure (Fuji II LC capsule, FL; Fuji Filling LC, FF) and one tri-cure (Vitremer, VT) RMGI restoratives were selected for this study. Their codes, manufacturers, types, compositions, batch numbers, and manufacturers' instructions for use are summarized in Table 1.

To prepare samples, two types of silicone molds were fabricated: one with cylindrical cavities, $5 \mathrm{~mm}$ diameter and $1 \mathrm{~mm}$ depth (mold "A" for measurements at a depth of $0 \mathrm{~mm}$, i.e., samples "A"), and the others with rectangular cavities, $5 \mathrm{~mm}$ width and $7 \mathrm{~mm}$ length (mold " $\mathrm{B}$ " for measurements at a depth of 1,2 , and $4 \mathrm{~mm}$, i.e., samples "B"), as shown in Figure 1 . The materials were mixed according to the manufacturers' instructions: FL using an amalgamator (ALMICJ, Yoshida Dental Mfg. Co., Ltd., Tokyo, Japan) and FF and VT by hand (Table 1). In mold A, the mixed material was transferred into the cavities placed on a polyester strip, covered with another polyester strip, and gently pressed to expel the excess material (Figure 1(a)). Mold B was placed on a polyester strip over a glass slide that had been covered with a black adhesive paper tape (black glass slide). The mixed material was filled into the cavities and then covered with another polyester strip and black glass slide. This assembly was pressed together by means of a clamp to displace excess material. The third polyester strip was placed onto the exposed RMGI material (Figure 1(b)). The filled RMGI material was then irradiated for $40 \mathrm{~s}$ by placing the end of the light guide of a dental light-curing unit (Elipar TriLight, 3 M ESPE, Seefeld, Germany; standard mode) onto the top of the polyester strip so that the light could transmit through the polyester strip over the material $(n=6)$ [10]. The $750 \mathrm{~mW} / \mathrm{cm}^{2}$ output intensity was constantly measured during the experiment by a built-in radiometer.

2.2. FTIR Spectroscopy. The samples were removed from the molds and analyzed with FTIR spectroscopy $10 \mathrm{~min}$, 1 day, and 7 days after light-irradiation [10]. The samples were stored in a dark container at $37^{\circ} \mathrm{C}$ with $100 \%$ relative humidity except during measurements. Before testing, all samples were blot-dried using a rubber air blower, and all soft material was scraped from the bottom of samples B. FTIR analysis was performed at $0 \mathrm{~mm}$ (at the center of the top surface of sample A) and 1,2, and $4 \mathrm{~mm}$ below the surface (along the central axes of samples B) of the cured materials using an FTIR spectroscope (IRPrestige-21, Shimadzu Corp., Kyoto, Japan) connected to an optical microscope (AIM8800, Shimadzu Corp.). The specular reflectance spectrum was acquired by scanning the samples 50 times over a $2000-1100 \mathrm{~cm}^{-1}$ range with a resolution of $4 \mathrm{~cm}^{-1}$ and then mathematically converted into an absorption spectrum via Kramers-Kronig (K-K) relations using IRSolution software version 1.21 (Shimadzu Corp.) [13, 14].

From each spectrum, the degree of conversion (DC) and the extent of acid-base reaction (EAB) of the material at each specified depth $(0,1,2$, or $4 \mathrm{~mm})$ and each observation time (10 $\mathrm{min}, 1$ day, and 7 days after light-irradiation) were calculated. The peak absorbance height of methacrylate $\mathrm{C}=\mathrm{C}$ bonds $\left(\mathrm{C}=\mathrm{C}\right.$ str at $\sim 1637 \mathrm{~cm}^{-1}$ ) was used as the analytical frequency, while the peak absorbance height of methacrylate ester bonds $\left(\mathrm{C}=\mathrm{O}\right.$ str at $\sim 1724 \mathrm{~cm}^{-1}$ ) was used as a reference frequency [7]. The DC was then calculated by comparing the $\mathrm{C}=\mathrm{C} / \mathrm{C}=\mathrm{O}$ peak absorbance height in the cured material with that in the uncured material, according to the following equation [15]: DC $(\%)=(1-C / U) \times 100$, where $C$ and $U$ are the normalized absorption peak heights of methacrylate $\mathrm{C}=\mathrm{C}$ bonds for the cured and uncured materials, respectively. To determine the efficiency of the acid-base reaction of the material, the complex ester peak at $\sim 1724 \mathrm{~cm}^{-1}$ was deconvoluted into three subpeaks at $\sim 1732, \sim 1724$, and $1708 \mathrm{~cm}^{-1}$ from each spectrum [7]. The peak absorbance height ratio of the carboxylate salts formed $(\mathrm{C}=\mathrm{O}$ str of COOM, $\sim 1562 \mathrm{~cm}^{-1}$ ) to the remaining unionized carboxyl groups $\left(\mathrm{C}=\mathrm{O}\right.$ str of $\mathrm{COOH}, \sim 1732 \mathrm{~cm}^{-1}$ ) was calculated. The $\mathrm{EAB}$ was determined using the following equation [7]: $\mathrm{EAB}=$ $C^{\prime} / U^{\prime}$, where $C^{\prime}$ and $U^{\prime}$ are the $C=O$ str of $C O O M / C=O$ str of $\mathrm{COOH}$ absorption peak height ratios for the cured and uncured materials, respectively.

2.3. Microhardness Measurements. The RMGI samples for microhardness measurements were prepared in the same way as for FTIR spectroscopy measurements. Using a Vickers hardness tester (HMV-2, Shimadzu Corp.), three indentations were made at each depth (each indentation separated by approximately $0.5 \mathrm{~mm}$ ) on each sample using a 10 -s dwell time and a 100-g load. The Vickers hardness (VH) at each depth for each sample was recorded as the average of the three readings $(n=6)$ [8]. 


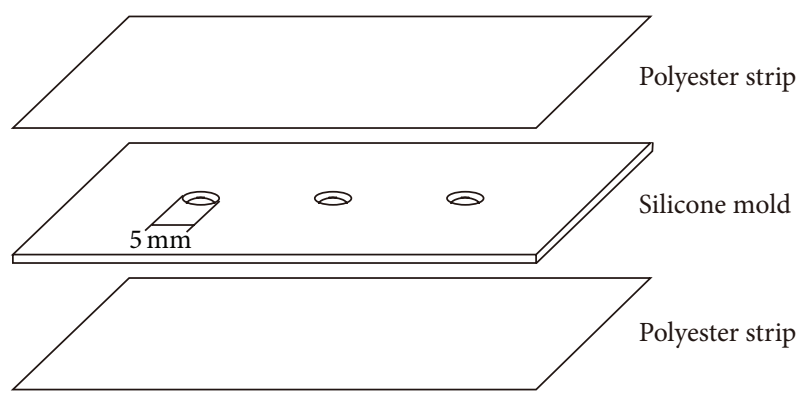

(a)

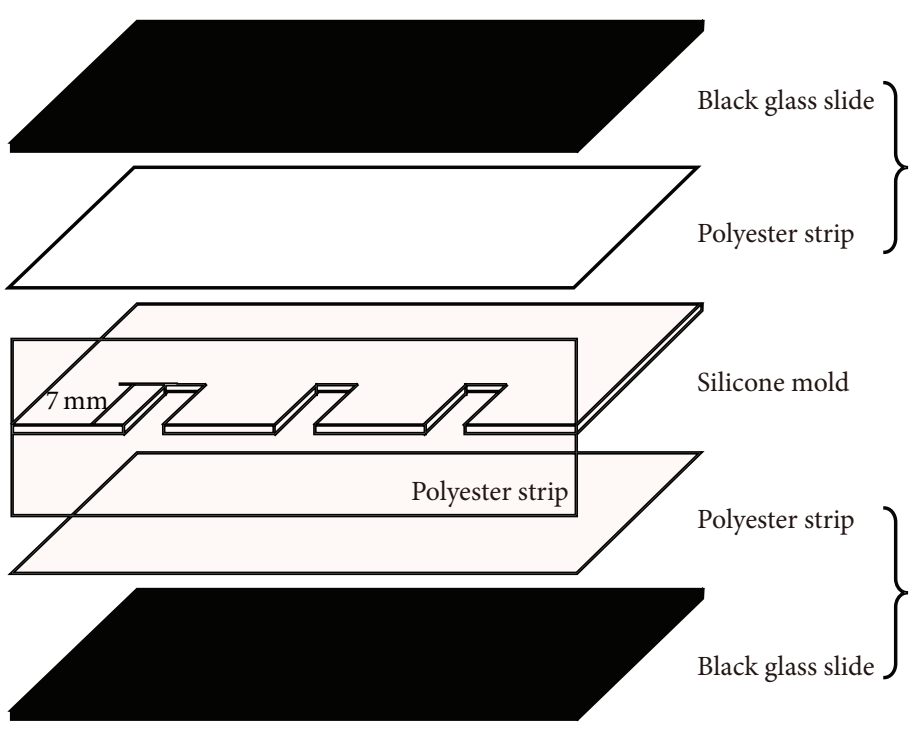

(b)

FIGURE 1: Two kinds of custom-made silicone molds simulating cavities prepared in a tooth: (a) for preparation of samples A (measurements at a depth of $0 \mathrm{~mm}$ ) and (b) for preparation of samples B (measurement at a depth of 1,2, and $4 \mathrm{~mm}$ ).

TABLE 1: Code, brand, manufacturer, type, composition, batch number, and manufactures' instructions of the materials used.

\begin{tabular}{|c|c|c|c|c|c|}
\hline Code (material) & Manufacturer & Type & $\begin{array}{l}\text { Composition } \\
\text { (manufacturer supplied) }\end{array}$ & Batch number (shade) & $\begin{array}{l}\text { Manufacturers' } \\
\text { instructions }{ }^{\mathrm{a}}\end{array}$ \\
\hline $\begin{array}{l}\text { FL (Fuji II LC } \\
\text { capsule) }\end{array}$ & $\begin{array}{l}\text { GC Corp., } \\
\text { Tokyo, Japan }\end{array}$ & Light-cure & $\begin{array}{l}\text { Powder: aluminosilicate } \\
\text { glass } \\
\text { Liquid: water, polyacrylic } \\
\text { acid, HEMA, UDMA, and } \\
\text { camphorquinone }\end{array}$ & $1009041(\mathrm{~A} 3)$ & $\begin{array}{l}\text { After activation, set the } \\
\text { capsule into a mixer, and } \\
\text { mix for } 10 \text { s. Light-cure for } \\
20 \text { s. }\end{array}$ \\
\hline $\begin{array}{l}\text { FF (Fuji Filling } \\
\text { LC) }\end{array}$ & GC Corp. & Light-cure & $\begin{array}{l}\text { Paste A: aluminosilicate } \\
\text { glass, HEMA, and UDMA } \\
\text { Paste B: water, polyacrylic } \\
\text { acid, UDMA, and silicon } \\
\text { dioxide }\end{array}$ & $1006091(\mathrm{~A} 3)$ & $\begin{array}{l}\text { After dispensing, mix } \\
\text { thoroughly with lapping } \\
\text { strokes for } 10 \mathrm{~s} \text {. Light-cure } \\
\text { for } 20 \mathrm{~s} \text {. }\end{array}$ \\
\hline VT (Vitremer) & $\begin{array}{l}\text { 3M ESPE, St. } \\
\text { Paul, MN, USA }\end{array}$ & Tricure & $\begin{array}{l}\text { Powder: } \\
\text { fluoroaluminosilicate glass, } \\
\text { microencapsulated } \\
\text { potassium persulfate, and } \\
\text { ascorbic acid } \\
\text { Liquid: copolymer of } \\
\text { acrylic and itaconic acids, } \\
\text { water, HEMA, and } \\
\text { diphenyliodonium } \\
\text { hexafluorophosphate }\end{array}$ & N136183/N173275 (A3) & $\begin{array}{l}\text { Place an equal number of } \\
\text { level powder scoops and } \\
\text { liquid drops. Mix the } \\
\text { powder into the liquid. } \\
\text { Light-cure for } 40 \mathrm{~s} \text {. }\end{array}$ \\
\hline
\end{tabular}

Monomer abbreviations: HEMA: 2-hydroxyethyl methacrylate; UDMA: urethane dimethacrylate.

${ }^{a}$ In the present study, all materials were light-irradiated for $40 \mathrm{~s}$.

2.4. Statistical Analysis. All of the data were compared statistically using one-way analysis of variance (ANOVA) and Duncan's multiple range tests at the 0.05 significance level $[10,16]$. The statistical analysis was performed using SPSS 17.0 for Windows (SPSS Inc., Chicago, IL, USA).

\section{Results and Discussion}

Using reflection measurements, IR spectra can be nondestructively obtained from a wide range of sample types. The specular reflectance technique often allows analysis with little 


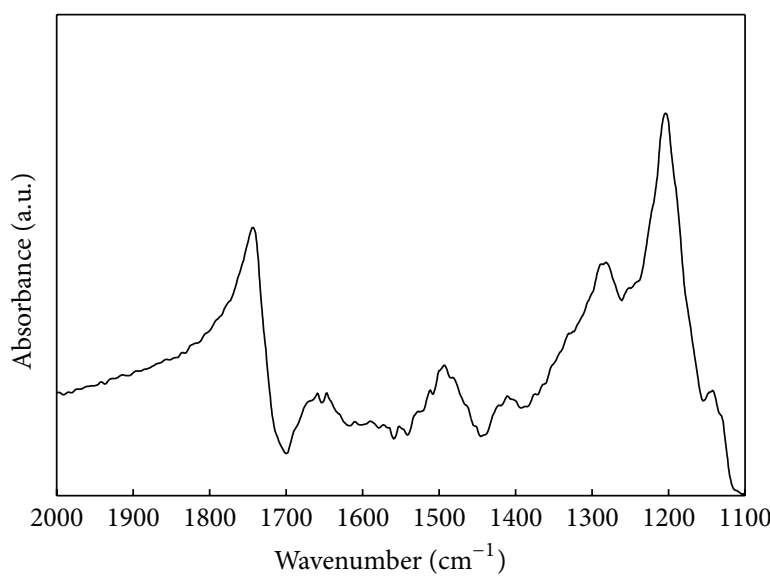

(a)

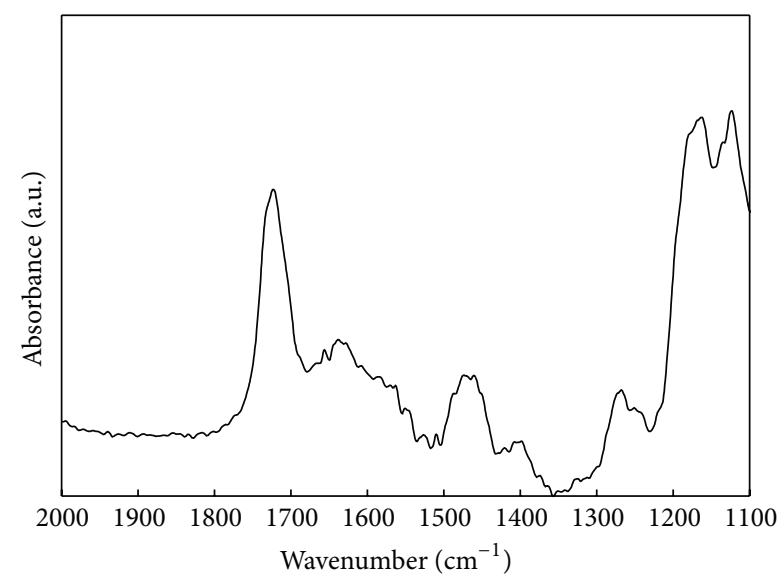

(b)

FIGURE 2: (a) Specular reflectance IR spectrum of an RMGI sample (before conversion). (b) Kramer-Kronig transformation of the reflection spectrum (after conversion).

sample preparation and keeps the sample intact for other measurements. However, wavelength-dependent changes in refractive index can yield anomalous bands in reflectance spectra and, as a result, make identification and functional group analysis difficult. Thus, this distorted spectrum should be converted into a normal absorption spectrum using a mathematical algorithm called the K-K transformation [13, 14]. In this study, the Maclaurin method, which provides better calculation accuracy than the double FFT method, was employed for the K-K conversion.

To obtain the specular reflectance spectra, flat, smooth, and shiny surfaces of the RMGI samples were prepared with a polyester strip and glass slide. Figure 2 shows the specular reflectance IR spectra before and after the K-K transformation [14]. To determine the EAB, the peak absorbance height of the unionized carboxyl groups was used for the calculation after the complex ester peak was deconvoluted from each spectrum (Figure 3) [7].

A command setting behavior in RMGIs is made by incorporating photopolymerizable monomers and suitable photoinitiation systems [4]. The light-curable versions of GIs include a photocurable component, which may be an unsaturated organic side chain grafted onto the poly(acrylic acid) backbone, and/or a separate organic precursor such as HEMA or mixtures of HEMA with other acrylic monomers [17]. Thus, HEMA is an important constituent of these hybrid materials. However, Anstice and Nicholson [17] demonstrated that the incorporation of even a small amount of organic compounds (including HEMA) into the liquid interferes with the normal acid-base reaction of an RMGI. Some dental RMGI products include approximately $15-20 \%$ HEMA in the liquid compartment, and when mixed with powder, there will be approximately 5\% HEMA in the set material $[8,9,18]$. Thus, the initial setting of an RMGI occurs as a result of the photopolymerization of HEMA when the material is light-irradiated after mixing. The DC results of the two light-cure and one tricure RMGI materials at different depths and postirradiation times are summarized in Table 2.
At the initial stage of the measurement, within 10 min after light-irradiation, the values of each material were statistically similar up to a depth of $2 \mathrm{~mm}$ compared to those at the top layer $(0 \mathrm{~mm})(P>0.05)$. Mount et al. [9] recommended the use of incremental placement of RMGI restoratives to allow for a full irradiation-initiated cure. In the two light-cure RMGIs (FL and FF), significantly lower 10 min DC values at a depth of $4 \mathrm{~mm}$ than those at the top layer indicate poor photopolymerization at the deep layer regions, probably due to substantial light attenuation [19].

In the tricure RMGI VT, the additional chemical polymerization mechanism was expected to contribute to the curing depth over time. Kakaboura et al. [7] suggested that chemical polymerization of VT can take place in a deeper cavity region where there is light attenuation and its slow rate can allow proper development of the acid-base reaction. In addition, VT employs a potassium persulfate/ascorbic acid redox initiation system (Table 1), which was developed by Antonucci et al. as a new initiator system for the ambient polymerization of dental monomers [20]. In this study, however, significant chemical polymerization reaction over time (up to 7 days) was not observed in the tricure material VT (Table 2). This finding suggests that photopolymerization was still predominant over chemical polymerization for VT [9]. However, it should be noted that differentiating the relative contribution of the two polymerization mechanisms (photo and chemical) to the setting of VT was not possible because the dark-curing condition (without the light-irradiation) was not included in the present study.

For all the materials tested, each DC value at the initial measurement was not significantly altered over time (up to 7 days) $(P>0.05)$ (Table 2). Although the clinical set (by acidbase reaction) of conventional GIs appears to be completed within a few minutes, a continuing maturation phase occurs over several months through posthardening reactions. For dental resin composites, in contrast, the significant polymerization reaction finishes within $24 \mathrm{~h}$ after mix or after light-activation [15]. Moreover, previous studies suggested 


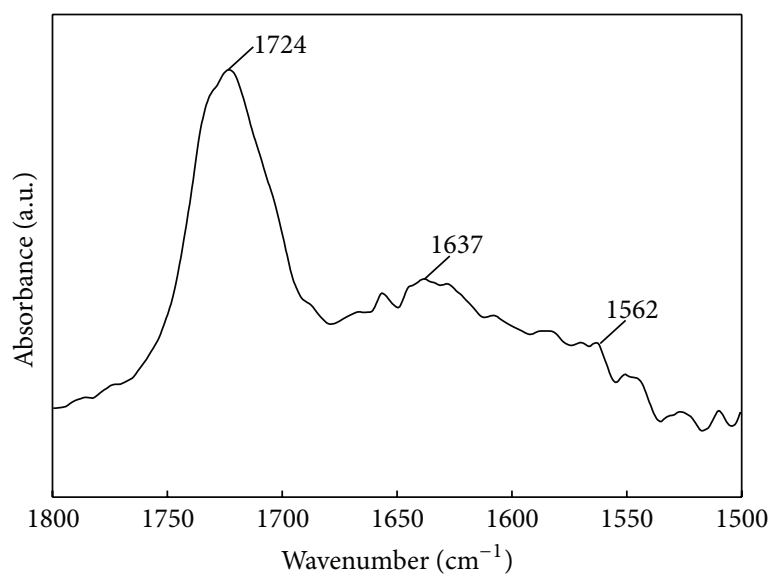

(a)

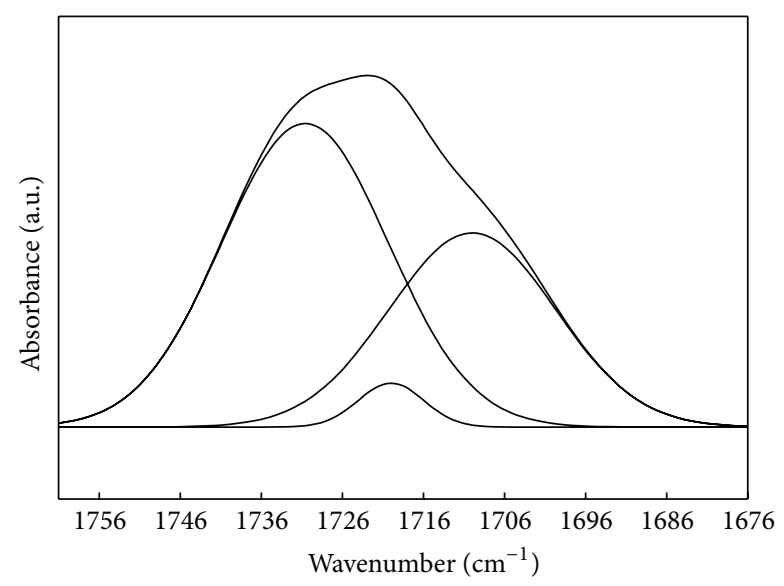

(b)

FIGURE 3: (a) FTIR spectrum of an RMGI sample in the range of $1800-1500 \mathrm{~cm}^{-1}$ : the peak at $\sim 1724 \mathrm{~cm}^{-1}$ indicates the ester bond (C=O str), the peak at $\sim 1637 \mathrm{~cm}^{-1}$ indicates the methacrylate $\mathrm{C}=\mathrm{C}$ bond $\left(\mathrm{C}=\mathrm{C}\right.$ str), and the peak at $\sim 1562 \mathrm{~cm}^{-1}$ indicates the carboxylate salt formed (C=O str of COOM). (b) Deconvolution of the complex ester peak into three subpeaks: unionized carboxyl groups at $\sim 1732 \mathrm{~cm}^{-1}, \sim 1724 \mathrm{~cm}^{-1}$ and ester groups dependent on substitution at $\sim 1708 \mathrm{~cm}^{-1}$.

TABLE 2: Degree of conversion (DC) (\%) of materials at different depths and postirradiation times (mean and SD in parentheses).

\begin{tabular}{|c|c|c|c|c|}
\hline Material & Depth & $10 \mathrm{~min}$ & 1 day & 7 days \\
\hline \multirow{4}{*}{$\mathrm{FL}$} & $0 \mathrm{~mm}$ & $46.0(6.1) \mathrm{a}$ & $47.2(4.8) \mathrm{a}$ & $47.8(6.0) \mathrm{a}$ \\
\hline & $1 \mathrm{~mm}$ & 44.5 (5.6) a & $46.1(3.0) \mathrm{a}$ & $45.2(5.8) \mathrm{a}$ \\
\hline & $2 \mathrm{~mm}$ & 42.3 (4.1) ab & $41.9(5.1) \mathrm{ab}$ & $44.8(4.4) \mathrm{a}$ \\
\hline & $4 \mathrm{~mm}$ & $34.6(3.8) c$ & $36.7(3.9) \mathrm{bc}$ & $37.3(4.2) \mathrm{bc}$ \\
\hline \multirow{4}{*}{$\mathrm{FF}$} & $0 \mathrm{~mm}$ & $56.5(4.0) \mathrm{a}$ & $58.6(4.1) \mathrm{a}$ & $58.5(5.7) \mathrm{a}$ \\
\hline & $1 \mathrm{~mm}$ & $53.4(6.7) \mathrm{a}$ & $52.7(3.9) \mathrm{a}$ & $54.9(2.6) \mathrm{a}$ \\
\hline & $2 \mathrm{~mm}$ & $52.9(6.8) \mathrm{a}$ & $54.8(4.4) \mathrm{a}$ & $52.6(4.4) \mathrm{a}$ \\
\hline & $4 \mathrm{~mm}$ & $37.5(3.7) \mathrm{b}$ & $39.0(3.4) \mathrm{b}$ & $41.2(4.6) \mathrm{b}$ \\
\hline \multirow{4}{*}{ VT } & $0 \mathrm{~mm}$ & $38.0(4.3) \mathrm{a}$ & $42.5(6.8) \mathrm{a}$ & $40.1(5.0) \mathrm{a}$ \\
\hline & $1 \mathrm{~mm}$ & $37.8(3.7) \mathrm{a}$ & $39.9(6.7) \mathrm{a}$ & $41.6(2.8) \mathrm{a}$ \\
\hline & $2 \mathrm{~mm}$ & $35.6(5.9) \mathrm{ab}$ & $37.4(3.2) \mathrm{a}$ & $38.5(3.6) \mathrm{a}$ \\
\hline & $4 \mathrm{~mm}$ & $29.6(5.1) b c$ & $28.2(4.5) c$ & $26.5(4.3) \mathrm{c}$ \\
\hline
\end{tabular}

Within the same material, means with same lowercase letters indicate no statistically significant difference between the groups $(P>0.05)$.

that $90 \%$ of the conversion obtained after $24 \mathrm{~h}$ is developed within the first $10 \mathrm{~min}$ in light-activated dual-cure resin composites $[15,21]$. The DC results in this study (Table 2) also show that the initial setting of RMGI restoratives by photopolymerization has a similar tendency to that of dental resin composites. In RMGIs, further polymerization after the initial set may be inhibited by the formation of the polysalt matrix [4].

The acid-base reaction of RMGI materials can contribute to the curing depth over time, independent of lightactivation. Table 3 presents the EBA of the materials as a function of curing depth and postirradiation time. At the initial stage of the measurement, the values of each material were statistically similar up to a depth of $4 \mathrm{~mm}$ compared to those at the top layer $(P>0.05)$, indicating that the acidbase reaction of the materials was depth independent. For FL and VT, the values consistently and significantly increased over time, regardless of the depth $(P<0.05)$. FF showed significantly higher values at 1 and 7 days than at $10 \mathrm{~min}$ at all the depths $(P<0.05)$. This finding shows that the acid-base reaction occurred up to 1 day (for FF) or 7 days (for FL and VT) after light-irradiation and that the reaction also seemed to be more efficient over time than chemical polymerization even for the tricure RMGI VT (Tables 2 and 3). The initial setting of the materials by photopolymerization may decrease the rates of diffusive processes of a gel matrix [11]. Moreover, the reduction in content of water, which is an essential component of the acid-base reaction, may retard the acidbase reaction [9, 11]. Kakaboura et al. [7] and Berzins et al. [12] demonstrated that the acid-base and photopolymerization reactions may compete with and inhibit one another during early RMGI development. However, in accordance with Wan et al. [11], the acid-base reaction of the three RMGI materials was delayed instead of being completely inhibited. Thus, the storage of the RMGI samples in humid condition seems to have allowed a relatively long-term acid-base reaction. It has 
TABLE 3: Extent of acid-base reaction (EAB) of materials at different depths and postirradiation times (mean and SD in parentheses).

\begin{tabular}{|c|c|c|c|c|}
\hline Material & Depth & $10 \mathrm{~min}$ & 1 day & 7 days \\
\hline \multirow{4}{*}{$\mathrm{FL}$} & $0 \mathrm{~mm}$ & $2.0(0.2) \mathrm{a}$ & $3.8(0.5) \mathrm{b}$ & $5.7(0.4) \mathrm{c}$ \\
\hline & $1 \mathrm{~mm}$ & $2.4(0.3) \mathrm{a}$ & $4.1(0.7) \mathrm{b}$ & $5.8(0.8) \mathrm{c}$ \\
\hline & $2 \mathrm{~mm}$ & $2.6(0.5) \mathrm{a}$ & $3.8(0.6) \mathrm{b}$ & $5.5(0.4) \mathrm{c}$ \\
\hline & $4 \mathrm{~mm}$ & $2.6(0.4) \mathrm{a}$ & $3.7(0.3) \mathrm{b}$ & $5.6(0.5) c$ \\
\hline \multirow{4}{*}{$\mathrm{FF}$} & $0 \mathrm{~mm}$ & $6.8(0.6) \mathrm{a}$ & $11.2(1.1) b$ & $12.5(1.6) b$ \\
\hline & $1 \mathrm{~mm}$ & $6.3(0.9) \mathrm{a}$ & $17.1(1.3) \mathrm{c}$ & $17.9(2.4) \mathrm{c}$ \\
\hline & $2 \mathrm{~mm}$ & $7.4(1.1) \mathrm{a}$ & $16.9(1.9) \mathrm{c}$ & $18.0(2.3) \mathrm{c}$ \\
\hline & $4 \mathrm{~mm}$ & $7.7(1.4) \mathrm{a}$ & $23.1(3.8) \mathrm{d}$ & $22.2(3.5) \mathrm{d}$ \\
\hline \multirow{4}{*}{ VT } & $0 \mathrm{~mm}$ & $1.3(0.2) \mathrm{a}$ & $2.6(0.4) b$ & $4.1(0.5) \mathrm{ce}$ \\
\hline & $1 \mathrm{~mm}$ & $1.0(0.1) \mathrm{a}$ & $2.9(0.4) \mathrm{b}$ & $4.5(0.4) \mathrm{e}$ \\
\hline & $2 \mathrm{~mm}$ & $1.1(0.2) \mathrm{a}$ & $3.7(0.5) \mathrm{c}$ & $4.6(0.7) \mathrm{e}$ \\
\hline & $4 \mathrm{~mm}$ & $1.3(0.2) \mathrm{a}$ & $5.5(0.9) \mathrm{d}$ & $6.4(0.8) \mathrm{f}$ \\
\hline
\end{tabular}

Within the same material, means with same lowercase letters indicate no statistically significant difference between the groups $(P>0.05)$.

TABLE 4: Vickers hardness (VH) of materials at different depths and postirradiation times (mean and SD in parentheses).

\begin{tabular}{|c|c|c|c|c|}
\hline Material & Depth & $10 \mathrm{~min}$ & 1 day & 7 days \\
\hline \multirow{4}{*}{$\mathrm{FL}$} & $0 \mathrm{~mm}$ & $34.7(3.3) \mathrm{a}$ & $29.6(4.0) \mathrm{a}$ & $31.8(4.4) \mathrm{a}$ \\
\hline & $1 \mathrm{~mm}$ & $32.5(4.5) \mathrm{a}$ & $30.4(3.2) \mathrm{a}$ & $29.6(3.4) \mathrm{a}$ \\
\hline & $2 \mathrm{~mm}$ & $30.4(3.6) \mathrm{a}$ & $31.1(5.4) \mathrm{a}$ & $33.4(2.9) \mathrm{a}$ \\
\hline & $4 \mathrm{~mm}$ & $22.0(1.8) \mathrm{b}$ & $31.5(3.1) \mathrm{a}$ & $34.8(3.3) \mathrm{a}$ \\
\hline \multirow{4}{*}{ FF } & $0 \mathrm{~mm}$ & $35.9(4.2) \mathrm{a}$ & $29.7(3.3) b$ & $27.1(3.6) b$ \\
\hline & $1 \mathrm{~mm}$ & $37.5(6.5) \mathrm{a}$ & $26.5(4.8) \mathrm{b}$ & $26.9(3.8) \mathrm{b}$ \\
\hline & $2 \mathrm{~mm}$ & $35.6(2.7) \mathrm{a}$ & $25.8(4.3) \mathrm{b}$ & $26.3(2.6) b$ \\
\hline & $4 \mathrm{~mm}$ & $31.0(3.8) \mathrm{b}$ & $28.9(3.5) b$ & $29.7(4.5) \mathrm{b}$ \\
\hline \multirow{4}{*}{ VT } & $0 \mathrm{~mm}$ & $16.0(3.3) \mathrm{a}$ & $16.2(1.6) \mathrm{a}$ & $20.4(3.7) b$ \\
\hline & $1 \mathrm{~mm}$ & 17.9 (2.7) ab & $17.9(3.0) \mathrm{ab}$ & $19.8(1.6) \mathrm{b}$ \\
\hline & $2 \mathrm{~mm}$ & $15.2(2.1) \mathrm{a}$ & $16.4(2.7) \mathrm{a}$ & $20.6(2.6) b$ \\
\hline & $4 \mathrm{~mm}$ & $5.3(1.3) \mathrm{c}$ & $14.7(3.2) \mathrm{a}$ & $15.8(1.9) \mathrm{a}$ \\
\hline
\end{tabular}

Within the same material, means with same lowercase letters indicate no statistically significant difference between the groups $(P>0.05)$.

been suggested that the initial increase in strength of GIs is mainly caused by the formation of metal carboxylates, after which the silicate network reconstruction plays a more significant role [22-24]. This second reaction through the growth of a silicate phase [22] was not investigated in the current SR-FTIR spectroscopy study, but it obviously requires further investigation to elucidate the setting mechanism of GIs with time.

The VH values of the RMGI materials are presented in Table 4. In general, the initial values (at $10 \mathrm{~min}$ ) showed a similar trend to the DC values (Table 2), indicating that the materials were initially hardened by photopolymerization. In $\mathrm{VT}$, the VH values gradually increased over time. In FF, in contrast, there were significant reductions in the value at 1 day, except at a depth of $4 \mathrm{~mm}$, compared to the initial values $(P<0.05)$. Previous studies using a shear punch strength test [9] or a Knoop hardness test [8] suggested that although the maturation process or slow chemical polymerization can occur over time in poorly or non-irradiated regions of RMGIs, these reactions may not be sufficient to compensate for photopolymerization. However, those tests did not directly investigate the DC or EBA values of the materials; instead, they only estimated the setting reaction from the mechanical properties of the hardened materials. Crosslinking of polymer chains may contribute to strengthening of conventional GIs, but water uptake may eventually decrease the physical properties of the materials [25]. Similarly, RMGI materials absorb water over time mainly due to the inclusion of the hydrophilic monomer HEMA, and the water sorption contributes to softening of the materials $[8,10]$. In this study, such a softening effect appeared prominent in FF (Table 4), implying that the material is more hydrophilic than the other two materials (Table 1). However, this observation should be further studied. Although microhardness measurement is a simple approach, it cannot be the final indicator for evaluating the setting of RMGI materials as a function of time. Moreover, the microhardness value is greatly influenced by material composition, and thus cross-comparison between the different RMGI brands is limited [15].

This in vitro study shows that SR-FTIR spectroscopy was more effective than microhardness tests for investigating the complex setting reactions of dental materials such as 
RMGIs. The spectroscopy results clearly show that the initial setting of dental RMGIs is made by photopolymerization and then the acid-base reaction progresses over time. Although the photopolymerization and acid-base reactions may be completed during the early setting stage $[7,12]$, the acid-base reaction progresses over time even at the well-light-irradiated superficial layers of the materials (Table 3) [11]. Thus, the incremental buildup of the restoration and increased exposure time are still recommended when the light source is distant from the cavity floor in order to maximize the physical and mechanical properties of the filled materials [9]. However, further experimental and clinical research is needed to elucidate the mechanisms of the long-term setting reaction of RMGI restoratives in the oral cavity.

\section{Conclusions}

(1) Sensitive SR-FTIR spectroscopy was an effective analytical method for investigating the setting reactions of dental RMGIs.

(2) The light-cure RMGI restoratives exhibited increased depth of cure over time by the acid-base reaction rather than photopolymerization. The improvement in depth of cure for the tricure material was also attributed to the acid-base reaction rather than chemical polymerization.

(3) Microhardness tests seemed less suitable for evaluating the setting of RMGI materials as a function of postirradiation time, probably due to the softening from the humidity.

\section{Conflict of Interests}

The authors declare that there is no conflict of interests regarding the publication of this paper.

\section{Acknowledgments}

This research was supported by Basic Science Research Program through the National Research Foundation of Korea (NRF) funded by the Ministry of Education (2013R1A1A2012382).

\section{References}

[1] M. J. Tyas and M. F. Burrow, "Adhesive restorative materials: a review," Australian Dental Journal, vol. 49, no. 3, pp. 112-154, 2004.

[2] J. W. McLean, J. W. Nicholson, and A. D. Wilson, "Proposed nomenclature for glass-ionomer dental cements and related materials.", Quintessence international, vol. 25, no. 9, pp. 587589, 1994.

[3] S. Saito, S. Tosaki, and K. Hirota, "Characteristics of glassionomer cements," in Advances in Glass-Ionomer Cements, C. L. Davidson and I. A. Mjör, Eds., pp. 15-50, Quintessence, Carol Stream, Ill, USA, 1999.

[4] H. F. Albers, Tooth-Colored Restoratives: Principles and Techniques, BC Decker, Hamilton, Canada, 9th edition, 2001.
[5] D. C. Smith, "Development of glass-ionomer cement systems," Biomaterials, vol. 19, no. 6, pp. 467-478, 1998.

[6] A. D. Wilson, "Resin-modified glass-ionomer cements," The International Journal of Prosthodontics, vol. 3, no. 5, pp. 425429, 1990.

[7] A. Kakaboura, G. Eliades, and G. Palaghias, "An FTIR study on the setting mechanism of resin-modified glass ionomer restoratives," Dental Materials, vol. 12, no. 3, pp. 173-178, 1996.

[8] H. W. Roberts, D. W. Berzins, and D. G. Charlton, "Hardness of three resin-modified glass-ionomer restorative materials as a function of depth and time," Journal of Esthetic and Restorative Dentistry, vol. 21, no. 4, pp. 262-272, 2009.

[9] G. J. Mount, C. Patel, and O. F. Makinson, "Resin modified glassionomers: strength, cure depth and translucency," Australian Dental Journal, vol. 47, no. 4, pp. 339-343, 2002.

[10] E. J. Swift Jr., M. A. Pawlus, M. A. Vargas, and D. Fortin, "Depth of cure of resin-modified glass ionomers," Dental Materials, vol. 11, no. 3, pp. 196-199, 1995.

[11] A. C. Wan, A. U. Yap, and G. W. Hastings, "Acid-base complex reactions in resin-modified and conventional glass ionomer cements," Journal of Biomedical Materials Research, vol. 48, no. 5, pp. 700-704, 1999.

[12] D. W. Berzins, S. Abey, M. C. Costache, C. A. Wilkie, and H. W. Roberts, "Resin-modified glass-ionomer setting reaction competition," Journal of Dental Research, vol. 89, no. 1, pp. 8286, 2010.

[13] P. Grosse and V. Offermann, "Analysis of reflectance data using the Kramers-Kronig Relations," Applied Physics A Solids and Surfaces, vol. 52, no. 2, pp. 138-144, 1991.

[14] M. A. Calin, R. M. Ion, and N. Herascu, "Kramers-Kronig analysis of 5,10,1,20-tetra-p-sulfonato-phenyl-porphyrin (TSPP) as photosensitizer for photodynamic therapy," Journal of Optoelectronics and Advanced Materials, vol. 7, no. 6, pp. 3155-3160, 2005.

[15] Y. L. Yan, Y. K. Kim, K.-H. Kim, and T.-Y. Kwon, "Changes in degree of conversion and microhardness of dental resin cements," Operative Dentistry, vol. 35, no. 2, pp. 203-210, 2010.

[16] H.-B. Ahn, S.-J. Ahn, S.-J. Lee, T.-W. Kim, and D.-S. Nahm, "Analysis of surface roughness and surface free energy characteristics of various orthodontic materials," The American Journal of Orthodontics and Dentofacial Orthopedics, vol. 136, no. 5, pp. 668-674, 2009.

[17] H. M. Anstice and J. W. Nicholson, "Studies in the setting of polyelectrolyte materials-part II: the effect of organic compounds on a glass poly(alkenoate) cement," Journal of Materials Science: Materials in Medicine, vol. 5, no. 5, pp. 299-302, 1994.

[18] S. K. Sidhu and T. F. Watson, "Resin-modified glass ionomer materials. A status report for the American Journal of Dentistry," The American Journal of Dentistry, vol. 8, no. 1, pp. 59-67, 1995.

[19] M.-J. Kim, K.-H. Kim, Y.-K. Kim, and T.-Y. Kwon, “Degree of conversion of two dual-cured resin cements light-irradiated through zirconia ceramic disks," Journal of Advanced Prosthodontics, vol. 5, no. 4, pp. 464-470, 2013.

[20] J. M. Antonucci, C. L. Grams, and D. J. Termini, "New initiator systems for dental resins based on ascorbic acid," Journal of Dental Research, vol. 58, no. 9, pp. 1887-1899, 1979.

[21] F. A. Rueggeberg and W. F. Caughman, "The influence of light exposure on polymerization of dual-cure resin cements," Operative Dentistry, vol. 18, no. 2, pp. 48-55, 1993.

[22] E. A. Wasson and J. W. Nicholson, "New aspects of the setting of glass-ionomer cements," Journal of Dental Research, vol. 72, no. 2, pp. 481-483, 1993. 
[23] S. Matsuya, T. Maeda, and M. Ohta, "IR and NMR analyses of hardening and maturation of glass-ionomer cement," Journal of Dental Research, vol. 75, no. 12, pp. 1920-1927, 1996.

[24] S. Shahid, R. W. Billington, and G. J. Pearson, "The role of glass composition in the behaviour of glass acetic acid and glass lactic acid cements," Journal of Materials Science: Materials in Medicine, vol. 19, no. 2, pp. 541-545, 2008.

[25] M.-A. Cattani-Lorente, C. Godin, and J.-M. Meyer, "Mechanical behavior of glass ionomer cements affected by long-term storage in water," Dental Materials, vol. 10, no. 1, pp. 37-44, 1994. 

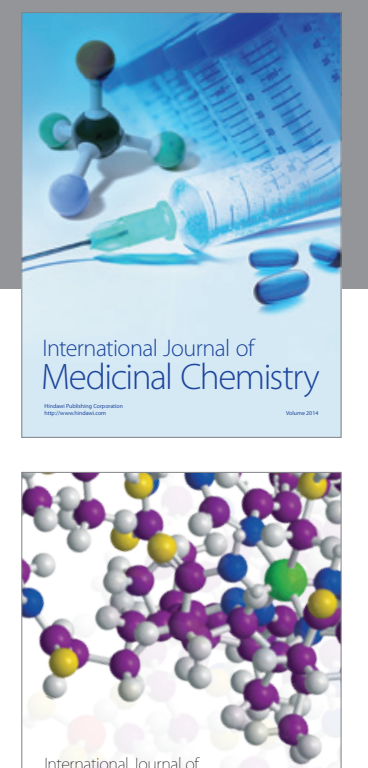

\section{Carbohydrate} Chemistry

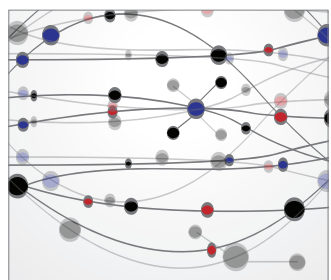

The Scientific World Journal
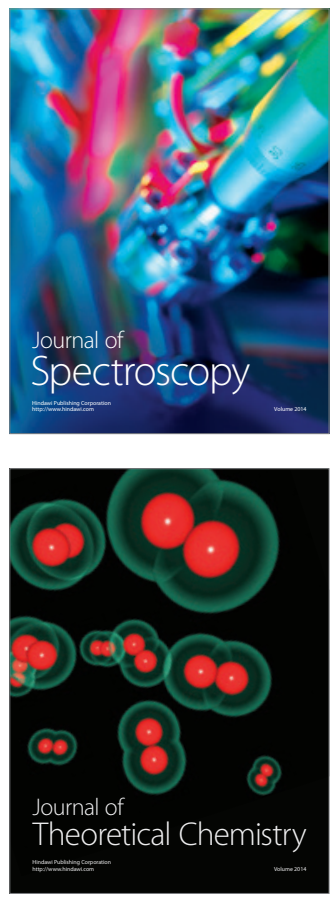
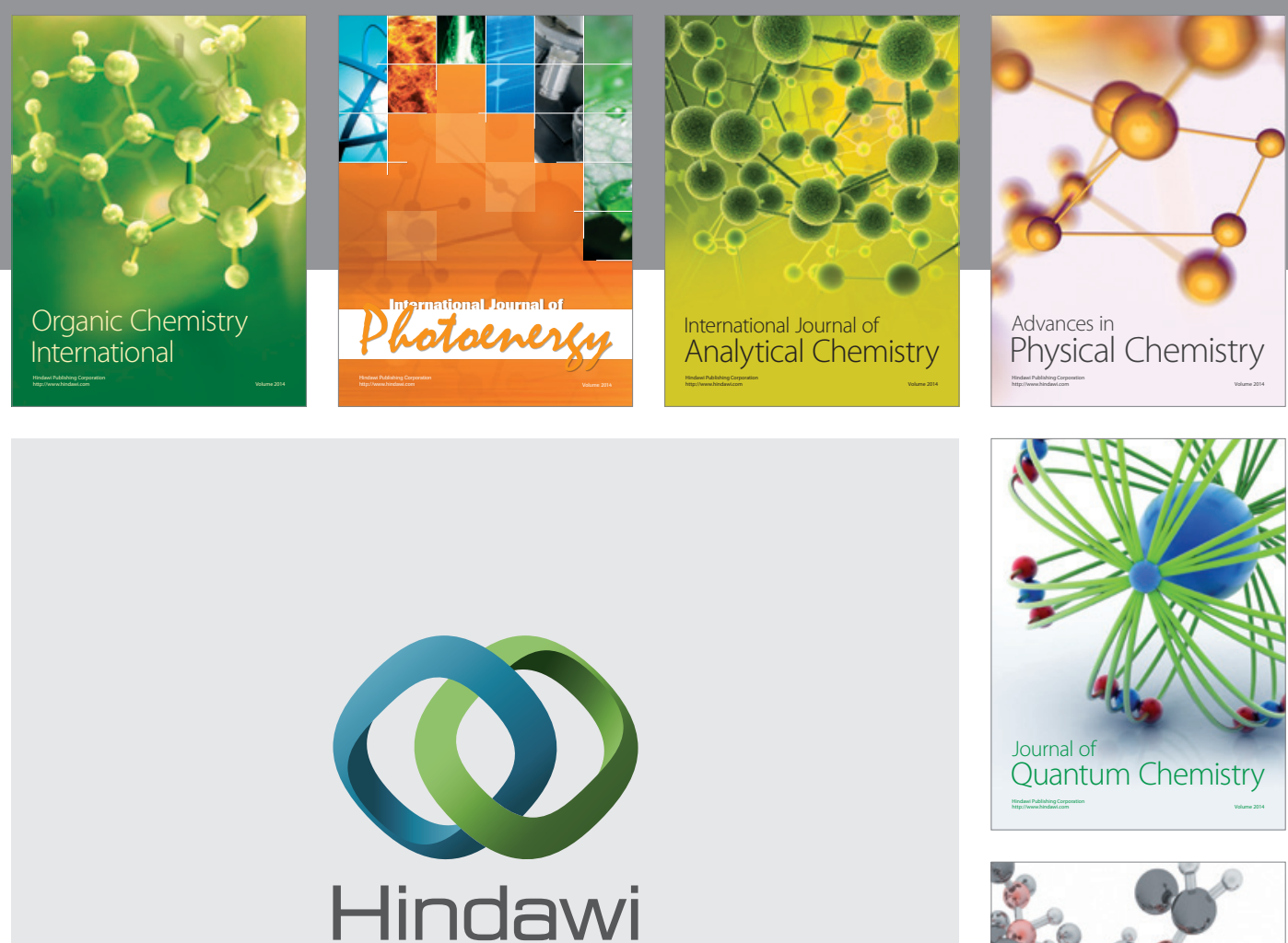

Submit your manuscripts at

http://www.hindawi.com

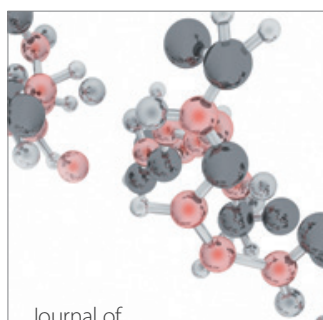

Analytical Methods

in Chemistry

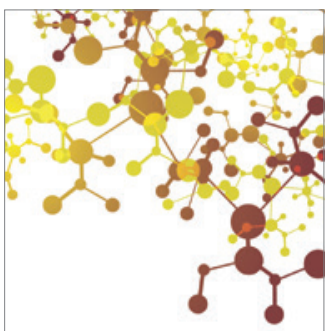

Journal of

Applied Chemistry

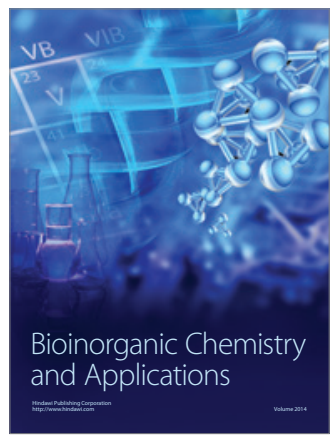

Inorganic Chemistry
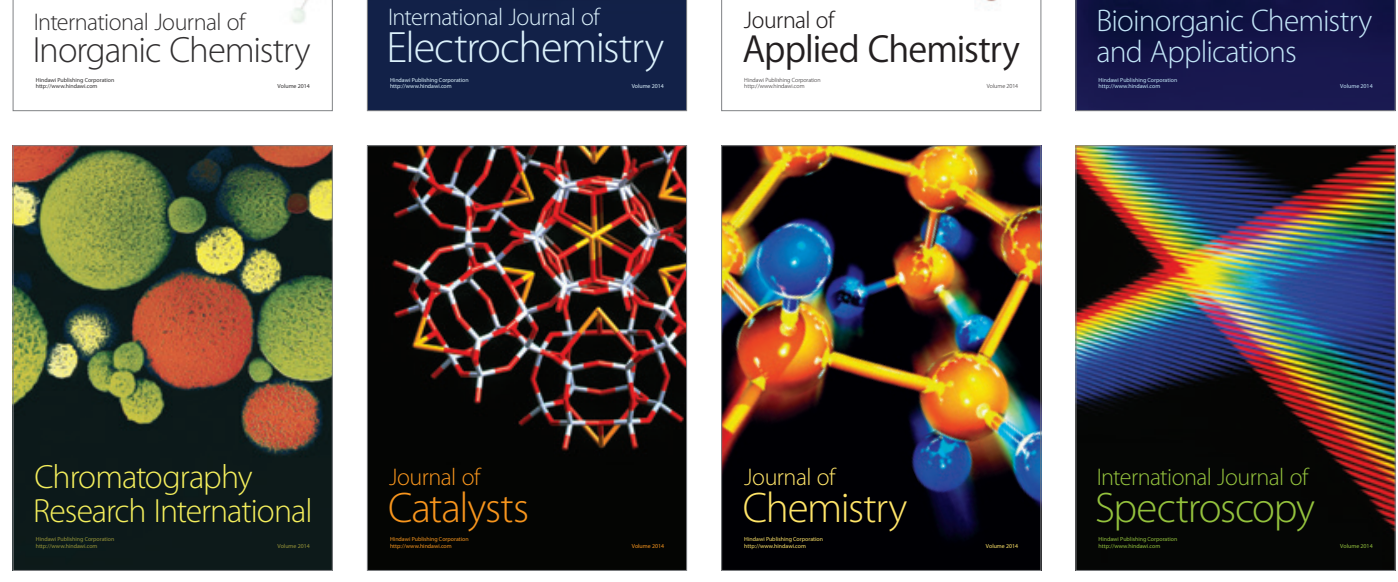